June 1990

\title{
An Historical Review of Electroconvulsive Therapy
}

Bruce A. Wright, M.D.

University of Pittsburgh Medical Center, Pittsburgh Pennsylvania

Follow this and additional works at: https://jdc.jefferson.edu/jeffjpsychiatry

Part of the Psychiatry Commons

Let us know how access to this document benefits you

\section{Recommended Citation}

Wright, M.D., Bruce A. (1990) "An Historical Review of Electroconvulsive Therapy," Jefferson Journal of Psychiatry. Vol. 8 : Iss. 2 , Article 10.

DOI: https://doi.org/10.29046/JJP.008.2.007

Available at: https://jdc.jefferson.edu/jeffjpsychiatry/vol8/iss2/10

This Article is brought to you for free and open access by the Jefferson Digital Commons. The Jefferson Digital Commons is a service of Thomas Jefferson University's Center for Teaching and Learning (CTL). The Commons is a showcase for Jefferson books and journals, peer-reviewed scholarly publications, unique historical collections from the University archives, and teaching tools. The Jefferson Digital Commons allows researchers and interested readers anywhere in the world to learn about and keep up to date with Jefferson scholarship. This article has been accepted for inclusion in Jefferson Journal of Psychiatry by an authorized administrator of the Jefferson Digital Commons. For more information, please contact: JeffersonDigitalCommons@jefferson.edu. 


\title{
An Historical Review of Electroconvulsive Therapy
}

\author{
Bruce A. Wright, M.D.
}

The initial clinical trial of electroconvulsive therapy (ECT) was performed by Ugo Cerletti and Lucino Bini at the University of Rome in 1938. The following paper will examine both the developments which led to the first trial of ECT, and the use of ECT over the subsequent fifty years. Hopefully, by investigating the historical aspects of the development and progression of ECT, a better understanding of this treatment modality can be attained.

The therapeutic use of electricity was not unique to ECT. There is evidence that Ancient Romans used the current generated by electric eels for the treatment of headaches, gout, and to assist in obstetrical procedures. The recent history of the therapeutic use of electricity dates to 1744 when the journal entitled "Electricity and Medicine" was first published. It was claimed here that electric stimuli could be curative for "neurologic and mental cases of paralysis and epilepsy (1)." J.B. LeRoy in the 1755 edition of "Electricity and Medicine" detailed a case of hysterical blindness which was cured with three applications of electric shock (1). In 1752, Benjamin Franklin recorded the use of an "electro static machine to cure a woman of hysterical fits (2)." By the mid 19th century the use of electrotherapy had so progressed that G.B.C. Duchenne (often referred to as the Father of Electrotherapy) would say, "No sincere neurologist could practice without the use of electrotherapy (1)."

But, despite the documented use of electrotherapy through the 19th century, there is little evidence that this was of any influence in the development of ECT. The historical emphasis in the medicinal use of electricity was on the electric stimulus in and of itself, whereas the electricity in ECT was used solely for its convulsant properties.

A more important contribution to the development of ECT was the work of Julius Wagner-Jauregg. It was a common observation in the late nineteenth century that a wide variety of disorders often improved clinically following febrile episodes. Wagner-Jauregg, in 1917, attempted to alleviate the symptoms of dementia paralytica (neuro-syphilis) by inducing fever with the intramuscular injection of blood from patients with malaria. Of the first nine patients he investigated, three had a complete recovery, three had a temporary symptom-

Address correspondence to Dr. Wright, Western Psychiatric Institute and Clinic, 3811 O'Hara Street, Pittsburgh, PA 15213 
atic relief of symptoms, and three had no clinical change (3). With this, WagnerJauregg essentially opened the door for the biological therapy of mental illness.

The 1930's were an exciting time in the treatment of schizophrenia. Three therapies,-all extrapolations of Wagner-Jauregg's theory-were developed within a several year period. These included: insulin induced hypoglycemia, pharmacologically induced convulsive therapy, and leukotomy. The first of these was Manfred Sakel's insulin induced hypoglycemia. Although the hypoglycemia induced by Sakel occasionally resulted in convulsion, he did not believe that the convulsion was therapeutically necessary. Rather, Sakel felt that the hypoglycemia restricted the activity of that portion of the central nervous system which was responsible for the psychopathology (4).

Sakel's technique was followed in 1934 by Ladislas Meduna's pharmacologically induced convulsive therapy, which will be discussed later. Then, in 1936, Egas Moniz developed the technique of leukotomy (lobotomy) for the treatment of psychosis. Moniz was later awarded a Nobel Prize in 1949 for his work on the psychosurgerical treatment on schizophrenia.

Ladislas Meduna, who graduated from the University of Budapest School of Medicine in 1921, attempted to treat schizophrenia by inducing seizures in his patients. This theory was based on what Meduna felt to be a "biologic antagonism between the epileptic state and schizophrenia (5)." Specifically, he observed clinically that patients with schizophrenia frequently had a decrease in their psychotic symptoms after spontaneous seizures. Moreover, based on autopsy findings, Meduna reported that epileptic brains were associated with a "hyperplasia" of the glial system while schizophrenic brains were associated with a "torpor" of this system (3). He therefore proposed that pharmacologicallyinduced seizures may be of benefit for the treatment of schizophrenia.

However, Meduna commented in his unpublished auto-biography:

... a this time, however, I did not dare to think of curing schizophrenia, partly because ... to us, schizophrenia was an endogenous, hereditary disease. Both expressions, endogenous and hereditary, meant that the fate of the patient was determined at the moment of conception; the disease anchored in the ovum and sperm; nothing could change that fate (6).

Despite his reservations, Meduna eventually decided to test his theory. On January 23, 1934, he gave an intramuscular injection of camphor oil to a patient who had been in a catatonic stupor for four years. Meduna described the dramatic improvement in this patient with five camphor oil induced seizures:

... on the morning of February 10, 1934, (two days after the fifth injection) for the first time in four years, he got out of bed, began to talk, requested breakfast, dressed himself without any help, was interested in everything around him, and asked how long he had been in the hospital. When we told him that he had spent four years, he did not believe it (6). 
After several trials with camphor oil, Meduna switched to pentylenetrazol (Metrazol) as the epileptogenic stimulant because it produced an immediate convulsion. Despite the initial criticism and opposition, pharmacologicallyinduced seizures remained a preferred treatment modality for schizophrenia until the advent of ECT.

In 1935, Meduna published "Versuche Uber Die Biologische Beeinflussung Des Ablaufes Der Schizophrenie" ("Attempts To Influence The Cause of Schizophrenia By Biological Means") which documented the results of his first twenty-six schizophrenic patients to have pharmacologically induced seizures (7). The results suggested that there did indeed seem to be an antagonistic relationship between schizophrenia and convulsive episodes. Ten of the twentysix patients reportedly improved while sixteen were without clinical improvement. Of note, the patients who did improve had received, on the average, 6.2 seizures; on the other hand, those who did not improve had an average of only two seizures per patient. Despite these results, Meduna's work was met with much criticism. Meduna, in his autobiography, recalled the reaction of Dr. Karl Schaffer, the department chairman at the University of Budapest:

... he (Schaffer) called me a swindler, a humbug, a cheat . . . how dare I claim that I cured schizophrenia, an endogenous, hereditary disease. He knew what was in my mind-to publish, get newspaper publicity, and make money! "If you dare publish this paper I disown you." . . . this incident was the first shock I received for the discovery of shock therapy (6).

Ugo Cerletti, the chair of the Department of Neuropsychiatry at the University of Rome, utilized Meduna's pharmaco-convulsive therapy for the treatment of his schizophrenic patients. Cerletti, whose laboratory research involved an examination of the histopathologic changes in Ammon's horn of dogs brains following electrically induced seizures, postulated that electricity could be substituted for Metrazol as the convulsive stimulus for the treatment of psychosis. However, Cerletti was reluctant to pursue this theory:

... the idea of submitting a man to convulsant electric discharges was considered as utopian, barbaric, and dangerous; in everyone's mind was the specter of the electric chair (6).

Cerletti's academic peers attempted to dissuade him from electrically inducing convulsions in man. Among the arguments used against his proposal was the idea that transcranial electricity was used to kill pigs in slaughter houses in Rome. However, Cerletti determined, in research he performed at local slaughter houses, that the pigs were actually put into an electrically-induced epileptic coma during which time their necks were slashed. Cerletti found that pigs could actually tolerate a significant voltage across the head without subsequent death.

Lucino Bini, who had no formal training in psychiatry, worked with Cerletti on the technical aspects of electrical convulsions. Bini noted that there was a 
high mortality in Cerletti's laboratory dogs following induced seizures. He determined that this was secondary to the Viale method of electrode placement in which the electrodes were placed in the dogs mouth and rectum. This permitted electrical current to travel through the heart and occasionally cause fatal arrhythmias. Bini subsequently initiated experiments with bitemporal electrode placement.

After significant deliberation and animal experimentation, Cerletti and Bini were prepared to attempt ECT in man. In April, 1938 the first ECT was performed by Cerletti and several members of his staff-Bini, Langhi, Acconero, and Kalinowsky. Cerletti described the first patient, a 40 year old schizophrenic:

... He expressed himself exclusively in an incomprehensible gibberish made up of odd neologisms and, since his arrival from Milan by train without a ticket, not a thing had been ascertainable about his identity (8).

Dr. Cerletti described the first ECT as follows:

... as was our custom with dogs, Bini and I fixed the two electrodes well wetted in salt solution, by an elastic band to the patient's temples. As a precaution, for our first test, we used reduced tension (70 volts) with a duration of 0.2 seconds. Upon closing the circuit, there was a sudden jump of the patient on his bed with a very short tensing of all his muscles; then he immediately collapsed on to the bed without loss of consciousness.

The patient presently started to sing at the top of his voice, then fell silent. It was evident from our experience with dogs that the voltage had been held too low (8).

At this point, there was controversy among the observers whether a repeat stimulus at a higher voltage should be attempted. In the midst of this discussion, the patient pleaded, in language that was no longer incomprehensible, "non una seronda! mortifera!" ("not again it will kill me!"). Cerletti decided, against the majority opinion, to repeat the electric stimulus:

I (Cerletti) had the electrodes reapplied, and a 110 volt discharge was sent through for 0.5 seconds. The immediate, very brief cramping of all the muscles was once again seen; after a slight pause, the most typical epileptic fit began to take place. True it is that all had their hearts in the mouths and were truly oppressed during the tonic phase with apnea, ashy paleness, and cadaverous facial cyanosis - an apnea which, if it be awe inspiring in a spontaneous epileptic fit, now seemed painfully never ending - until at the first deep, stertorous inhalation, and first chronic shutters, the blood ran more freely in the bystanders veins as well: and, lastly, to the immense relief of all concerned, was 
witnessed a characteristic, gradual awakening by step. The patient sat up of his own accord, looked about him calmly with a vague smile, as though asking what was expected of him. I asked him "what has been happening to you?" He answered, with no more gibberish: "I don't know, perhaps I have been asleep (8)."

The initial patient received thirteen more treatments of ECT over a two month period and was discharged in complete remission. Unfortunately, the patient was lost to follow-up after two years; but, he remained symptom free until that time. The first public presentation of ECT was given by Cerletti at the Medical Academy of Rome in May, 1938. ECT gradually gained acceptance for the treatment of schizophrenia across Europe and by 1943 it had crossed the Atlantic and was being used in America.

Although ECT, at its inception, was used primarily for the treatment of schizophrenia, investigators explored the efficacy of this treatment modality for the entire gamut of psychiatric disorders. Within several years, ECT was a relatively common treatment for the affective disorders, especially depression with psychotic features and severe mania. Approximately 15 years after the first trial of ECT, Jarrie estimated, in a paper on the treatment of affective disorders, that one third of the 60,000 hospitalized patients in England and Whales would receive ECT (9).

The use of ECT was not without potential side-effects and complications. Among these problems were a risk of fractures (especially of the extremities and spinal compression fractures), a relatively high degree of psychic distress experienced by the patients, and cognitive changes following treatments. Several advances were made over the subsequent years to alleviate these problems. Bennet, a psychiatrist, was instrumental in determining the muscle-relaxing agent used by South American hunters to paralyze their prey. He was able to use this agent, curare, during ECT and therefore significantly decreased the risk of fractures (10). Succinyl-choline was later substituted for curare because of its improved side-effect profile (11). In addition to muscle relaxants, barbiturates were administered both to decrease the patient's subjective anxiety prior to treatment and to decrease the anxiety associated with paralysis. With respect to the cognitive changes, it was determined that the unilateral, as opposed to bitemporal, administration of the electrical current would still result in a generalized seizure and was less likely to produce cognitive changes. These advances significantly decreased the complications and side-effects associated with ECT.

The use of ECT in the 1940's was flourishing as there was no other effective treatment for psychiatric disorders. However, with the introduction of neuroleptic medication, and subsequently antidepressants, ECT was used with decreasing frequency. The administration of psychotropic medication was less time consuming and certainly did not have the stigma associated with it that ECT did. In 
addition, much of the funding for research on the treatment of psychiatric disorders was provided by pharmaceutical companies.

The psychotropic medications were not, however, the panacea that many people had hoped. They did not have $100 \%$ cure rate and were also associated with occasional side-effects and complications. Thus, despite the decline in ECT use following the introduction of psychotropic medication, the 1980's saw a gradual resurgence of ECT. In the United States in 1980, 2.5\% of all hospitalized psychiatric patients received ECT; and 13\% of all patients admitted to a hospital with a primary diagnosis of an affective disorder received ECT (10). While it is difficult, if not impossible, to perform a statistically sound study of the efficacy of ECT, it has been suggested that ECT is at least as effective, if not more effective, in the treatment of depression than psychopharmacologic interventions.

Despite the resurgence of ECT, this continues to be an extremely controversial treatment for psychiatric disorders. The negative aspect of ECT is advanced by movies like One flew Over The Cuckoo's Nest and the anti-psychiatry movement. Sources like these often advance the view that ECT is a psychiatric tool of punishment and retribution.

In conclusion, the use of electricity for therapeutic purposes dates to ancient medicine. However, the concept of using electricity as a convulsive agent for the treatment of psychiatric disorders can be directly traced to the pharmacoconvulsive therapies of Meduna. Over the years, significant improvements have been made in the administration of this treatment in order to significantly decrease the associated adverse effects. At the present time, ECT appears to be as effective as pharmacologic interventions for the treatment of psychiatric disorders. But, for many reasons, including the social stigma associated with its use, ECT is most frequently used only as a last line of therapeutic intervention.

\section{REFERENCES}

1. Harm E: The origin and early history of electrotherapy and electroshock. Am J Psychiatry 111:933, 1955

2. Palmer RL: The history of shock treatment, in Electroconvulsive Therapy: an Appraisal. Edited by Palmer RL. Oxford University Press, Oxford, 1981, p. 3

3. Fink M: Convulsive Therapy: Theory and Practice. Raven Press, New York, 1981

4. Sakel M: The methodologic use of hypoglycemia in the treatment of psychosis. Am J Psychiatry 94:111-129, 1937

5. Meduna LV, Friedman E: The convulsive-irritative therapy of psychoses. JAMA 112:501-509, 1939

6. Fink M: Meduna and the origins of convulsive therapy. Am J Psychiatry 141:10341041, 1984

7. Meduna LJ: Versuche uber die biologische beeinflussung des ablaufes der schizophrenia: Campher und cardiozolkramphe. Zeitschrift Fur Die Gesante Neurologie Und Psychiatrie. 152:235-262, 1935

8. Cerletti U: Old and new information about electroshock. Am J Psychiatry 107:87, 1950 
9. Jarrie HF: Prognosis of depression treated by electric convulsive therapy. 1:132134,1954

10. Bennet AE: Preventing traumatic complications in convulsive shock therapy by curare. JAMA 114:322-324, 1940

11. Thompson WT, Blaine JD: Use of ECT in the United States in 1975 and 1980. Am J Psychiatry 144:5559, 1987

12. Holmberg G, Thesleff S: Succinyl-choline-iodide as a muscular relaxant in electroshock therapy. Am J Psychiatry 108:842-846, 1952 